\title{
INNOVATION AND BUSINESS CYCLES
}

\author{
Agnès Festré
}

\section{Introduction}

There is something surprising in the fact that Schumpeter's theory of business cycles has received considerably less attention from members of the profession than some of his other contributions such as, in particular, his theory of innovation and entrepreneurship or his ideas on firm concentration and technological competition. A number of commentators have drawn attention to this differential treatment of Schumpeter's theory of the business cycle vis-à-vis other parts of his work, most notably among these some of the contributors to Cunningham Wood's collection of Critical Assessments of Schumpeter who have provided a number of explanations for its relative lack of success.

Madaràrsz, author of the introduction to the Hungarian edition of the Theory of Economic Development, quotes Perroux, a French expert on Schumpeter, to highlight the fact that

the inner tension of Schumpeter's work on business cycles derives from the 
centuries old dilemma of political economics and economic theory that is due to the relationship between abstract logic analysis and the historical and sociological approach. Schumpeter's theory of development is precisely an attempt to reconcile these two approaches, translating into the language of marginal utility theory and abstract deductive general equilibrium theory the wealth of historical school concerning succeeding economic systems, primarily capitalism.

(Perroux 1965: 189).

Madaràrsz concludes that Schumpeter did not succeed in this attempt. This plausible explanation contrasts with the view provided by Elliot who argues that the failure of Schumpeter's theory of the business cycle to achieve the same seminal reputation as other aspects of his work was mainly due to unfortunate timing. Not only did the outbreak of World War I shift economists' attention to more immediate practical questions which clearly did not enter into Schumpeter's attempt to reconstruct economic analysis and to redirect it towards a radically new path. More importantly, the publication in 1936 of Keynes' General Theory further reinforced this shift in emphasis since by the time Schumpeter published Business Cycles in 1938, depression had begun to abate and the exigencies of World War II focused most economists' minds on the more immediately relevant issues raised by Keynes. While this was for the great benefit of Keynesian analysis, it was also to the detriment of 
Schumpeter's more abstract concerns. ${ }^{1}$.

Focusing on the relation between Schumpeter's two main contributions on business cycles, the Theory of Economic Development (1912) and Business Cycles, Hansen provides a still different account of the profession's lack of receptivity for Schumpeter's theory of the business cycle. While acknowledging that the Theory of Economic Development established Schumpeter's international reputation, Hansen maintains that it would be difficult to make a similar claim about his later work. In his view,

the first book comparatively small, presents a central idea in a bold, imaginative, dashing, colorful, and eloquent style; the second, a massive two-volume work, rich in historical learning, takes cognizance of a vast analytical literature but only as a side issue in the process of unfolding the author's own argument.

(Hansen 1991 (1951): 212-213).

This view is shared by Freeman who, however, rightly points out that Schumpeter's later work on business cycles has been the subject of renewed interest in the 80s judging, in particular, by the explosion of international conferences dedicated to the theory of long cycles to which Schumpeter's work

\footnotetext{
${ }^{1}$ See J. E. Elliot 1985.
} 
is of central importance. ${ }^{2}$ This recent reappraisal of the Business Cycles has prompted an extensive debate on controversial aspects of Schumpeter's approach, such as his views on equilibrium and the role he attributes to innovation in the theory of business cycles.

Even though these debates have certainly been illuminating by focusing attention on the inconsistencies in Schumpeter's work, their major drawback is that they have side-lined the truly original element of his theory of business cycles. As Schumpeter himself has always claimed, the specificity of his approach consists precisely in providing a first approximation towards a better understanding of the relationships between innovation and business cycles. As a matter of fact, Schumpeter's theory of business cycles differs considerably from most of his contemporaries contributions in the field.

On the one hand, Schumpeter's views contrast with the tradition of 'endogenous' business cycle theory represented in the work of Aftalion or Keynes. This holds that the occurrence of cycles reveals the existence of shortterm disequilibria due either to the time lag between changes in the data and the adaptation of productive structures, or to the destabilizing influence of money and the portfolio choices of economic agents. However, these theories leave no room for the role of technological factors in the explanation of business cycles.

\footnotetext{
${ }^{2}$ See C. Freeman $1993: 18$.
} 
On the other hand, Schumpeter's approach differs from Walrasian tradition to the extent that the latter conceptualises observed paths of cycles and growth as deviations from the hypothetical long-term equilibrium path of the economy, ensuring steady and sustained growth. In this framework, technical change and innovation are treated as exogenous shocks disturbing this equilibrium. Much the same could be said about more recent contributions to real business cycle theory and to the new endogenous growth theory, with the exception of Aghion and Howitt who can be regarded as direct successors to Schumpeter insofar as they attempt to provide an endogenous explanation of the occurrence of technological innovations.

The main purpose of this chapter is to assess the originality of Schumpeter's theory of business cycles. The first section outlines the distinctive features of Schumpeter's approach to business cycles and economic dynamics. Section two looks at the mechanisms constituting the cycle in Schumpeter's two major contributions on this subject, the Theory of Economic Development (1911) and Business Cycles (1939).

\section{The distinctive features of Schumpeter's business cycle theory}

Schumpeter always regarded business cycles not as a minor or highly specialised subject of economic theorizing but as the most important 
manifestation of the dynamics of a capitalist economy. Hence, in the preface to the Business Cycles, he argued that

(a)nalysing business cycles means neither more nor less than analysing the economic process of the capitalist era (...) Cycles are not, like, tonsils, separable things that might be treated by themselves, but are, like the beat of the heart, of the essence of the organism that display them.

According to Hansen, Schumpeter was one of five continental economists whose work on business cycles laid the foundations for modern macroeconomics. ${ }^{3}$ More specifically, he maintained that Schumpeter's central message was 'that a dynamic society is constantly being drawn away from neighborhoods of equilibrium by reason of the pioneering activities of daring innovators whose lightning successes entice a swarm of imitators into a wild outpouring of new investment activity.' (Hansen [1951] 1991: 209). It is worthwhile mentioning here that Schumpeter's views on the stability of capitalism seem to have been much more radical than those endorsed by Keynes. As emphasized by Wolfson (1958 [1991]: 198), Keynes raised

\footnotetext{
3 The four other economists mentioned by Hansen are Wicksell (Geldzins und Güterpreise, 1898), Tugan-Baranowsky (Studien für Geschichte der Handelskrisen in England, 1901), Spiethoff ("Vorbemerkungen zu einer Theorie der Überproduction", Jahrbuch für Gestzgebung, Verwaltung und Volkswirtschaft, 1902) and Aftalion ("Essai d'une Théorie des crises générales et périodiques”, Revue d’Economie Politique, 1909).
} 
questions about the inherent stability of capitalism by analysing the values of crucial economic variables in situations of involuntary unemployment. However, the suggestion implicit in this analysis is that, given the 'right' values, stability at full employment is attainable. In contrast, Schumpeter believes that instability is of a structural nature and an inherent characteristic of the process of capitalist accumulation.

In 1952, he distinguishes between two opposing views of economic processes:

There is the 'theory' that the economic process is essentially nonoscillatory and that the explanation of cyclical as well as other fluctuations must therefore be sought in the particular circumstances (...) which disturb that even flow (...) And there is the 'theory' that the economic process itself is essentially wave-like -that cycles are the form of capitalist evolution.

(Schumpeter 1952: 252)

Schumpeter clearly adheres to the latter view, whereas his Austrian contemporary Hayek, whose work on business cycles grew out of the same continental business cycle school, advocates the former. The comparison with Hayek is not accidental since Schumpeter himself dedicated several passages of the Business Cycles to Hayek's theory of the trade cycle, contrasting it with his 
own views on economic dynamics including his conception of the rate of interest and capital accumulation. ${ }^{4}$. The main differences in their respective approaches may be summarized as follows:

To begin with, even though both Schumpeter and Hayek take as the starting point of their analysis a stationary equilibrium state, they do not attribute the same meaning nor the same analytical scope to this notion. Schumpeter effectively interprets the notion of equilibrium in terms of his well-known concept of the circular flow economy without investment or savings. The same is obviously not true of Hayek's approach according to which the amount of real savings constitutes the upper limit of sustainable investment. However, this initial difference is not as essential as might appear at first sight. In particular, the route taken by Schumpeter does not imply that he ignores growth-related factors such as saving. Rather, in his view, observed fluctuations are the result of a combination of this and other factors driving change. Thus, it would be more correct to say that Schumpeter eliminates savings not from his model as such but rather from its "basic skeleton”, as he puts it. Before going into more detail, it should be remembered that Schumpeter's treatment of saving and investment is, generally speaking, rather idiosyncratic ${ }^{5}$, as his basic definition of saving demonstrates:

\footnotetext{
${ }^{4}$ See Schumpeter 1939: 78 (fn.), 296 (fn.), 333, 345 (fn.), 603 (fn.), and 634.
} 
By Saving we mean the earmarking, by an household, of an element of its current receipts -as distinguished from “capital gains”- for the acquisition of titles to income or for the payment of debt. If a firm does the same thing with an element of its net receipts from the sale of products and services, we shall speak of Accumulation. The distinction between Saving and Accumulation also applies, although it may be difficult to carry out, in cases in which, as in the case of many farmers, 'firm' and 'household' are one. We confine both concepts to decisions about monetary funds and we neglect, for convenience’s sake, any similar decision that may be taken with respect to commodities. Saving and Accumulation will thus be treated as elements of a monetary process : the complementary process in the world of goods constitute a distinct problem.

In other words, his notion of saving stresses the fact that not only the bulk of individual saving but also all business saving is done with a specific investment purpose in mind. This implies that, as a rule, the decision to invest precedes the decision to save, and that the act of investing does so more often than not. It follows, first, that unless agents perceive investment opportunities, they will not normally save and that a situation characterised by a decline in investment

\footnotetext{
${ }^{5}$ See E. Staley $1986: 9$.
} 
opportunities is likely also to be characterised by a decline in saving. Consequently, most sources of savings as well as most motives for the act of saving would be absent from a stationary state. To put it another way, the bulk of savings flows from revenues or elements of revenues, namely profits, which do not exist in a stationary state. Second, since cash holdings are not regarded as claims to income ${ }^{6}$, Schumpeter's definition of saving excludes all considerations related to the Keynesian notion of liquidity. As a matter of fact, Schumpeter regarded the concepts of demand for money stocks and of liquidity preference as two examples of Keynes' "dei ex machina” - approach which, he felt, should be replaced by one that derived its concepts from a thorough analysis of the economic processes underlying surface phenomena. ${ }^{7}$

A second point of difference between Schumpeter's business cycle theory and that of Hayek - as well as the "Keynesian - Robertsonian - Swedish" approach concerns Schumpeter's claim that the malfunctioning of the equilibrium mechanism between saving and investment cannot, as such, provide an explanation of crises or depression:

\footnotetext{
${ }^{6}$ Cash holdings do not, in fact, belong to the 'business sphere' (Schumpeter, 1939/I: 124) also referred as the 'commodity sphere' or 'sphere of circulation' ((1917) 1956: 176), in which the national product circulates among social groups with the help of bank-credit. They are, instead, included in the 'sphere of hoard and reserves' which, together with the 'sphere of capital', constitutes the 'money market' ((1917) 1956: 176). This market permits, in turn, the working of stock markets. See R. Arena and A. Festré 1996: 168-169.

${ }^{7}$ See J. A. Schumpeter $1936: 795$.
} 
Actually, of course, we find that that equilibrium mechanism very often does not work. But sound diagnostic cannot be expected from denying its existence or from setting up such entities as ‘optimism', 'pessimism', 'saving instinct', or from simply asserting that people elect to act in such a way that maladjustment will ensue and that saving and investment can each go its own way indefinitely. In order to make headway, we must locate the sources of the trouble. They will be found in the business situations incident to the process of economic change we are about to describe, and link up with not spending and with variations in real investment rather than with savings. At the moment, however, it is desirable, since the ground is so fertile in misconceptions, to make quite sure that the saving-investment mechanism, as such, does not produce anything that could qualify for the role of an explanation of crises or depressions.

More generally, Schumpeter excludes growth factors, such as saving or accumulation by firms and households or even changes in population, from his definition of dynamics. This contrasts with Hayeks's view who regards the voluntary decision to save as a driving factor of capital accumulation and therefore expansion, whereas Schumpeter maintains that economic development and business cycles involve qualitative change. Given that the 
economic system is capable of absorbing the effect of the above mentioned growth factors without undergoing any substantial transformation, these factors cannot, by themselves, create the alternation of booms and depressions that can be observed. Rather, such growth factors, and saving in particular, owe their mainly quantitative role for capitalist dynamics to another driver of change innovation - without which the modus operandi of saving in the capitalist world cannot be understood. Schumpeter puts it thus:

That rudiment of a pure economic theory of development which is implied in the traditional doctrine of the formation of capital always refers merely to saving and to the investment of the small yearly increase attributable to it. In this it asserts nothing false, but it entirely overlooks much more essential things. The slow and continuous increase in time of the national supply of productive means and of savings is obviously an important factor in explaining the course of economic history though the centuries, but it is completely overshadowed by the fact that development consists primarily in employing existing resources in a different way, in doing new things with them, irrespective of whether those resources increase or not. In the treatment of short epochs, moreover, this is even true in a more tangible sense. Different methods of employment, and not saving and increases in the available quantity of labor, have changed the face of the economic world in the last fifty years. The increase in 
population especially, but also of the sources from which savings can be made, was first made possible in large measure through the different employment of the then existing means.

This immediately clarifies that, starting from Schumpeter's basic framework of the 'circular flow', the only logically conceivable means of financing innovations, if they are to occur at all, consists in credit-creation, not saving. Since the process of innovation involves the displacement of already existing factors of production, and since there are no previously accumulated idle financial resources available, new sources of purchasing power have to be created. This precisely is Schumpeter's rationale for the introduction of bank credit into his theory of economic development.

To be sure, saving and innovation are interdependent but innovation is the prime driver of cyclical dynamics. This does not imply that once the cyclical process has started, a model based on savings as the only means of financing economic activity could not be perceived of. However, since the modus operandi of innovation can be understood without taking account of accumulated savings once one allows for credit-creation, the point is that there is no need to take recourse to saving as an explanatory factor. 
Of course, Schumpeter is well aware of other ways to finance firm expenditures (out of previous receipts, the sale of assets, issuing bills of exchange, etc. ${ }^{8}$ ). He chooses to abstract from these alternatives in order to avoid complications arising from mechanical effects of these additional flows of funds on the running of businesses. ${ }^{9}$. As has been mentioned above, what this means is that saving can be ignored only in Schumpeter's basic analytical skeleton, i.e. the circular flow, not however at those stages of his theorising geared towards a more encompassing approximation of reality. This is a typical example of Schumpeter's methodology. As he himself reminds the reader in the Business Cycles: 'The stationary assumptions (...) have importance only for the purpose of preliminary clarification and are admitted from the outset to yield an inadequate picture which, taken by itself, would only mislead.' (1939/I: 78, fn 1).

As is well known, Schumpeter's theory of the business cycle comprises three successive approximations to reality. The first of these is contained in the last chapter of the Theory of Economic Development and referred to as his pure model of business cycles consisting of only two phases: prosperity and depression. Even though this basic framework abstracts from many specific features of economic movement, Schumpeter regards it as useful precisely because it isolates the most essential elements of the cycle from the

\footnotetext{
${ }^{8}$ See J. A. Schumpeter 1939 (vol. II): 578.
} 
‘innumerable layers of secondary, incidental, accidental and 'external' facts and reactions' that 'cover the skeleton of economic life, sometimes so as to hide it entirely' (1939/I: 137).The second approximation incorporates more complex features of business cycles already mentioned in the Theory of Economic Development but analyzed in more detail in the Business Cycles. These additional aspects of cycles, such as, for example, the intrusion of speculation, are seen to cause 'secondary waves' over and above the underlying 'primary waves’. Finally, the third approximation, developed in Business Cycles and known as the 'Kondratieff-Juglar-Kitchin three-cycle' scheme, distinguishes cycles of different lengths and amplitudes. Hence, once Schumpeter's analysis progresses from the first to subsequent approximations, the mentioned growth factors can no longer be discarded. ${ }^{10}$

A typical example of analytical extensions of this kind is provided by Schumpeter's description of the case of 'steady-growth':

We will envisage a society, stationary in every respect, except in that it displays a positive rate of saving. Production functions are invariant and external disturbances are absent. There is a positive rate of interest. We exclude -but this is only for the sake of convenience and brevity- all investment opportunities except lending to firms (this merely excludes

\footnotetext{
${ }^{9}$ See C. E. Staley 1986 :306.
} 
consumers' credit and assumes that saving is the only source of supply of such monetary means as these firms may wish to have in addition to their current receipts (this assumption excludes credit-creation (...)) We start from competitive equilibrium (...). Now, that equilibrium is incessantly disturbed by the flow of new savings which are being offered to firms. If, however, the system is adapted to the actual rate of savings (...) this disturbance will be currently absorbed; for, as long as saving goes on at all, each installment will depress the rate of interest to the extent required to create its own investment opportunity (...) And (...) the combination which is optimal now requires an increase in the more durable elements, let us call them machinery, such as will exactly equal the additional saving offered both in value and cost, which is what we mean by saving creating its own demand (...) The result would, in fact, be a steady growth of the system's industrial outfit by the steady addition to it of new units of plants and machinery, which, however, must be of the same types as those which are already in use or would be in use but for lumpiness, in order to exclude a new and different element which would otherwise intrude.

(1939/I: 79-80)

Even though unusual, it is not surprising that Schumpeter includes the case of steady growth under 'statics'. He simply regards it as an extension of the pure

${ }^{10}$ On this point, see K. Date 1961. 
model of the 'circular flow' to allow for a positive rate of saving. Even so his ultimate purpose in introducing this case to the analysis is to create an organic link between the 'circular flow' and the case of 'economic development'.

To sum up, the main reason for excluding some basic factors governing a capitalist economy from the framework of the 'circular flow', or the first approximation of business cycles, is that Schumpeter 'interprets them not as part of the capitalist process as such, but merely as the consequence of capitalist development' (Madaràsz 1991: 227). This does not, however, imply that they should also be ignored at later stages of approximation, in particular not when it comes to gaining a better understanding of how new actors, new institutions or new economic functions emerge once the domain of static analysis is left behind.

The 'steady-growth' case described above exemplifies this. What it tells us is that positive rates of interest and saving, or even the existence of banks may be brought into the picture in the process of broadening the concept of the circular flow. However, the 'raison d'être' of these additional factors is essentially linked to the logic of dynamic economic analysis. From this perspective, the pure case of economic development cannot properly be conceived of as 'the counter-pole of the circular flow' in that 'the negative definitions of the circular flow would constitute the essence of development’' (Madaràsz 1991: 227). 
Rather, it describes the interplay of economic factors resulting exclusively from the emergence of innovations. In other words, for Schumpeter economic development cannot be set into motion by any of the conventional growth factors. Even though these will exert some influence on the path of economic development, such development essentially takes place due to innovation only.

Obviously, this notion of dynamics is rather unconventional. All development begins with the 'entrepreneur-innovator' who 'steps on the scene as the demiurgos of the capitalist process of development [and] every category is tailor-made to suit him.' (Madaràsz 1991:229). With this in mind, we now turn to a more detailed discussion of the mechanisms constituting the business cycle in Schumpeter's theory.

\section{The mechanisms in Schumpeter's theory of the business cycles}

In the above section, we have focused on the originality of Schumpeter's conception of dynamic as opposed to static analysis. We have, in particular, pointed out that what Schumpeter means by 'statics' contrasts with the meaning more commonly attributed to the term and clarified first by Frisch and later by Samuelson: 
Statical refers to the form and structure of the postulated laws determining the behavior of the system. An equilibrium defined as the intersection of a pair of curves would be statical. Ordinary, it is 'timeless' in that nothing is specified concerning the duration of the process, but it may very well be defined as holding over time

(Samuelson 1943: 59)

By contrast, and as seen above, Schumpeter considers a state of 'steady-growth' of the form defined in the previous section as belonging to the domain of 'statics', even though positive values for both the rates of interest and saving as well as a constant rate of growth of consumption and production are possible. Thus, it seems that Schumpeter's use of the term 'statics' also refers to what is usually associated with a 'stationary’ situation, defined by Samuelson as follows:

Stationary is a descriptive term characterizing the behavior of an economic variable over time; it usually implies constancy, but is occasionally generalized to include behavior periodically repetitive over time. Used in this sense, the motion of a dynamic system may be stationary : e.g., the behavior of a pendulum satisfying Newton's laws of Motion, but subject to no disturbance and hence remaining at rest; or the behavior of national income after a change in investment has given rise to dwindling transient 
geometric progressions of the usual 'block-diagram’ character.

(Samuelson 1943: 59)

Likewise, Schumpeter's concept of 'dynamics' does not coincide with a more conventional notion of dynamic analysis since the latter does not exclude the study of stationary systems. In Schumpeter's view, the conventional growth factors, and saving in particular, do not qualify as explanatory factors of economic development. The kind of change produced by, for instance, an increase in the rate of saving is likely to be absorbed by a circular flow economy and cannot, hence, account for the occurrence of recurrent business cycles. Consequently, it is not the time dimension that is the distinctive feature of dynamic analysis. However, as we shall see, Schumpeter essentially regards 'dynamics’ as referring to non-stationary phenomena, i.e. systems on an irreversible path.

Thus, Schumpeter draws a clear-cut distinction between 'statics' from 'dynamics' on the grounds that they not only deal with distinct subject-matters but also require different methods and data. As he puts it, 'they are not two distinct chapters of a same edifice but rather two entirely separate edifices'(1908: 182). For Schumpeter, the essential difference between the circular flow or steady growth, on the one hand, and dynamic analysis, on the other, is that the latter is concerned with a type of change that cannot be dealt 
with on the basis of established routines, but rather upsets these. In other words, the existence of 'dynamics’ or development means doing things in a new way or doing new things. Although, at his stage, this appears to be rather a broad concept, Schumpeter, in fact, attributes a very specific meaning to the notion of development: It proceeds by way of innovations defined as 'the setting up of a new production function’ (1939/I: 87), including the emergence of new commodities, new forms of organization, the opening up of new markets or new sources of supply, changes in the way existing goods are made or any way of doing things differently. Moreover, development is a dynamic process that is endogenously driven, i.e. from within the system, and that has its own endogenous mechanism of propagation or diffusion. This latter is characterized by non-linearities which account for the recurrent emergence of business cycles. As Schumpeter puts it:

By 'development', therefore, we shall understand only such changes in economic life as are not forced upon it from without but arise by its own initiative, from within. Should it turn out that there are no such changes arising in the economic sphere itself, and that the phenomenon that we call economic development is in practice simply founded upon the fact that the data change and that the economy continuously adapts itself to them, then we should say that there is no economic development. 
In terms of this definition, economic development cannot be generated by any external factors. This, however, raises the question as to what differentiates innovation from any other factor driving change. Paradoxical though this may appear, Schumpeter regards innovation as the single cause of development without providing a clear explanation of its endogenous emergence. What Schumpeter is saying is that innovation implies historical and irreversible changes in the way of doing things and is generally associated with the activity of particular individuals (the ‘entrepreneur-hero’) establishing new businesses, thus triggering off an endogenous process of adaptation that unfolds its own dynamics within the economic system.

As Witt (1995) has stressed, Schumpeter contrasts the notion of innovation with the notion of invention. This distinction may help to clarify the notion of an endogenous process of innovation in Schumpeter's analysis. It draws attention to the fact that there is, indeed, an exogenous factor driving the emergence of novelty which is, however, confined to the domain of inventions. For Schumpeter, inventions are abundantly available and known to many people. Moreover, he argues that how such inventions came about is irrelevant for economic analysis. As Witt has argued, 'all that matters in his theory is the pioneering initiative, the 'doing it', the carrying out of what is already available but which no one has yet ventured to realize. Consequently, Schumpeter 
elaborates upon the psychology of his “entrepreneur-hero”' (1995: 85). Under the impact of novelty, the economic system moves away from the initial equilibrium position and experiences comprehensive changes which govern the process of adaptation and adjustment, and which ultimately account for the return of the system towards a neighbourhood of equilibrium. Thus, Schumpeter's theory is all about the dissemination of novelty in the market and in the economy as a whole, starting from a position of equilibrium. Since, in his view, a state of stability is also the condition for a new surge of innovation, the business cycle really is nothing else than the ebb and flow of innovation, including the repercussions, or 'secondary waves', generated by it.

This leads us to a closer examination of how the process of evolution starts. In Schumpeter's pure model, i.e. in his first approximation of business cycles, innovation comes to bear on a system in full-employment general equilibrium with zero profits, a zero rate of interest, where total receipts equal total costs which, in turn, equal total wages plus firm rents, and where, consequently there is no incentive for change. Innovation is the work of a new firm creating new production facilities. This new firm is led by a new economic agent called 'entrepreneur' to be distinguished from the 'mere manager' prevailing in the 'circular flow' whose activities are the product of 'routinized' behaviour. This entrepreneur has recourse to credit newly created by banks in order to finance the undertaking. As a matter of fact, since there are no previously accumulated 
financial resources in the circular flow, a new source of purchasing power has to be introduced into the economic system: '[The entrepreneur] (...) must resort to credit if he wishes to carry out a new combination, which cannot like an established business be financed by returns from previous production.' (1934: 69).

Schumpeter's preoccupation with the financial aspect of innovation and business cycles, which is the subject of another contribution to this volume ${ }^{11}$, may explain his relative neglect of the role technology. As has been pointed out with frequency by critics, Schumpeter's conceptualization of innovation is fairly limited. Freeman, for instance, stresses that Schumpeter fails to pay sufficient attention to some aspects of the diffusion of innovations, such as the interaction of science and technology, the cumulative nature of technological development, the technological as well as economic interdependence of many innovations and the existence of technological trajectories. Instead, he substituted a theory of entrepreneurship for a theory of the firm and innovation. ${ }^{12}$ This line of criticism is supported by Witt who attributes this flaw in Schumpeter's analysis to his distinction between invention and innovation. The chief feature of this distinction is that it permits him to circumvent both the problem of the emergency of novelty as well as the related problem of “subjective action knowledge” (1995: 85).

\footnotetext{
${ }^{11}$ See A.Festré in this volume on 'Money, Banking and Dynamics : Hayek vs. Schumpeter'.
} 
How then does Schumpeter describe the cycle? The money borrowed from the banks provides the innovator with the funds to employ the factors of production (acquire the factor inputs) required to set up his business. Given the assumption of initial full employment, these factors will have to be diverted away from old businesses.

However, this employment in new processes does not produce a rise in global output until after the period of gestation of the innovation. This defines the prosperity phase of the cycle characterised by rising prices in the sector or market affected by the innovation as well as in the economy as a whole due to the fact that, while the output of old industries that loose factors of production, falls, aggregate monetary demand increases in line with the newly created credit. Once the innovators' output finally reaches the market, two successive phases take place:

First, there is the process of the dissemination of the innovation via a 'swarm' of imitators based in related industrial sectors, beginning with the production lines that are closest to the innovation and ending with the most distantly related areas of production:

We know the reasons why this is likely to happen in the same field or in -

12 See C. Freeman 1993: 22-23. 
technologically, as well as economically- related fields : although in some respects a successful innovation will make other innovations easier to carry out in any field, it primarily facilitates them in the lines in which it may be directly copied as a whole or in part or for which it opens up new opportunities.

It should be stressed that at this stage, there are no losses in the economy as a whole, since, although some old firms may experience diminishing receipts or even losses, all old firms taken together benefit from the increasing aggregate demand and, thus, show a net surplus. More precisely, while meeting part of the rising cost of labour, this additional cost is covered by the increase in earnings from workers' spending on consumption:

In spite of the losses in some industries which must, under such circumstances, be expected to be a feature of the situation, all old firms taken together will, of course, show a net surplus. Of this we can satisfy ourselves if, disregarding everything except the first two steps -i.e., disbursements by entrepreneurs and again the next disbursement by income receivers- we assume that labor is the only factor, wages are the only cost. Then old firms will, obviously, have to pay but a part of the increase in the income of those workmen whom they still retain while 
they will, at the second turn of the wheel and before the new products reach their markets, receive the whole of it (...).

(1939/I: 132)

Hence, the diffusion or imitation phase of the innovation is characterized by higher values of the new products, reduced costs in general and pronounced industrial expansion. By way of illustration, Schumpeter discusses the case of existing products being produced on the basis of a new production function ${ }^{13}$, even though, in the Theory of Economic Development, he argues that 'the vast majority of new combinations will not grow out of the old firms or immediately take their place, but appear side by side, and compete, with them.' (1934: 226). However, in his view, it is immaterial

whether the innovator withdraws the necessary means of production from the branch of industry which hitherto manufactured the same commodity, or whether he allows existing firms to continue working in the habitual manner and begins to produce alongside of them with the new method and withdraws the necessary means of production from quite different branches of industry.

\footnotetext{
13 See J. A. Schumpeter 1934: 141.
} 
Ex hypothesis, the result will always be a higher value of the new products relative to those produced prior to the innovation with the same quantities of means of production. ${ }^{14}$

This raises the question as to where this higher value originates. Schumpeter maintains that it is not to be imputed to the factors of production because 'there would be no sense in imputing beforehand the surplus value of the new combination to the means of production, since the carrying out of it would then no longer appear as an advantage.' (Ibid.: 141). There are two main reasons why the services of labour and land have to be estimated at their old values, i.e. the values they were assigned in the circular flow. On one hand, 'the old values are customary values. Long experience has determined them, and they are established in the consciousness of individuals. They are only altered in the course of time and under the pressure of further long experience.'(Ibid.: 142). On the other hand, 'the entrepreneurial activity of the leader, which is indeed a necessary condition of the realization of the combination, may be conceived as a means of production.' (Ibid.: 143). By contrast, the values of the new products, just as their prices, do not form part of the pre-existing system of values. They are disequilibrium values that foreshadow the new equilibrium price structure which will establish itself once the process of adaptation is complete. They are, thus, essentially of a temporary nature. To begin with,

\footnotetext{
${ }^{14}$ See J. A. Schumpeter 1934: 141.
} 
absolute as well as relative prices do not change. Relative prices may vary only to the extent that 'the marginal value [of the means of production] in the previous uses indeed rises in consequence of the withdrawal of means of production from them.' (1934: 144). As expansion proceeds, price variations affect all means of production and products as the massive expansion of entrepreneurial demand implies a general increase in purchasing power across all areas of production affected by the original innovation:

Only because new purchasing power goes in bulk from the hands of entrepreneurs to the owners of material means of production, to all producers of goods for 'reproductive consumption' (...), and to the workers, and then oozes into every economic channel, are all existing consumption goods finally sold at ever-rising prices. Retailers thereupon place bigger orders, manufacturers extend operations, and for this purpose increasingly more unfavorable and often already abandoned means of production come into use again. And only on this account do production and trade everywhere temporarily yield a profit, just as in a period of inflation (...). Many things float on this 'secondary wave', without any new or direct impulse from the real driving force, and speculative anticipation in the end acquires a causal significance. The symptoms of prosperity themselves finally become, in the well known manner, a factor of prosperity. 
In this perspective, the surplus generated by successfully implementing new combinations, i.e. the capitalist entrepreneur's profit 'is not only a private but also a social phenomenon (...)' (1934: 143). In fact, even though, to begin with, this profit is captured by the innovator - Schumpeter labels it the 'promoter's profit' (1934: 137) - , the forces of competition will gradually work towards the emergence and establishment of a new structure of values. But the intrusion of new products will not, at first, affect the supply-side of the economy so as to cause any tangible change in the business situation as a whole.

However, this should not distract from the more 'disaggregated' features of the process of diffusion. Thus, it is important to recall the fact that innovations have an asymmetric effect on economic agents and their productive activities. As Schumpeter points out, under the impact of novelty,

for some of the 'old' firms new opportunities for expansion open up : the new methods or commodities create New Economic Space. But for others the emergence of the new methods means economic death; for still others, contraction and drifting into the background. Finally, there are firms and industries which are forced to undergo a difficult and painful process of modernization, rationalization and reconstruction. 
These sectoral investment shifts constitute a distinctive feature of Schumpeter's business cycles analysis. In contrast to most of his contemporaries, Schumpeter regards production structures or the various levels of activity that constitute the whole production system - individual firms, inter-firm or inter-sector links as well as the resulting aggregate level of production- as essential components of economic activity. Since innovation and evolution alter the way in which commodities are produced, the resulting changes in the composition of the productive system are an important part of dynamic analysis. Thus, a preoccupation with, for instance, the vertical composition of capital, as defined by Austrians like Hayek or von Mises, already implies a rejection of aggregate analysis. However, according to Schumpeter, this particular notion fails to account for the transfer of resources that characterizes 'the process by which the effects of the entrepreneurial activity spread (...) over the whole system, dislocating values, disrupting the equilibrium that existed before.' (1939/I: 132). Schumpeter, therefore, prefers an even more disaggregated approach to the analysis of economic processes. That is, he focuses on that level of analysis which permits a better, albeit always incomplete, understanding of the essential characteristics of the mechanisms of technological diffusion.

These vital parts of the mechanism of economic evolution, which are 
readily seen to dominate many business situations and to produce results of fundamental importance, can never be revealed statistically by measuring variation in an index of production, or analysed theoretically in terms of total output. Such an index would display nothing except increase. But mere increase in total output would not produce those effects. It is disharmonious or one-sided increase and shifts within the aggregative quantity which matter. Aggregative analysis, here, as elsewhere, not only does not tell the whole tale but necessarily obliterates the main (and the only interesting) point of the tale.

Similarly, the end of the expansion phase and the ensuing process of adaptation cannot be accurately understood if one sticks to aggregate analysis. Indeed, Schumpeter focuses attention on the fact that as the process of expansion gathers momentum and the mechanisms of imitation take over, propagation and self-reinforcement effects steadily gain in importance and disequilibrium begins to show. What this implies is that the sectoral shifts and the redistribution of income and wealth that follow the introduction of novelty are the chief feature of economic movement. Moreover, taking account of these factors also provides the key to understanding the cyclical nature of economic activity over time. 
To return to the second phase of the cycle, namely depression, this is characterized by a fall in prices and profits. Now, if, as Schumpeter quoting Juglar maintains ‘the only cause of the depression is prosperity’ (1934: 223), the causes of a slack in entrepreneurial activity must be determined on theoretical grounds. Schumpeter argument runs as follows:

(S)ince entrepreneurial activity characteristically starts off in a definite direction and does not distribute itself equally over the industrial field since it aims typically at production of a given commodity or group of commodities- its possibilities are, in every instance and in any given state of the economic body, definitely limited. The results of innovation act directly on certain individual prices, and therefore set definite limits on further advance in that direction or related directions.

More specifically, even if all existing and future producers correctly foresee the fall in prices due to the increased production and availability of the new product, a point should be reached at which this product will be produced at minimum unit cost which equals its price.

Moreover, the disturbance of the equilibrium system of values caused by an innovation and reinforced by the release of the new products triggers a process 
of adaptation to the changing situation. This ongoing revision of the values of all elements of the system impairs the calculation and planning abilities of economic agents. Under these circumstances, potential new entrepreneurs prefer to wait until things settle down rather than to run the risk of business failure. As a consequence, the decline of entrepreneurial demand for financial means together with the repayment of loans granted to entrepreneurs push the economy towards deflation and depression. Even though Schumpeter does not provide a general explanation, he suggests that, just as the expansionary phase, the cumulative downward process is also limited, that is it gradually peters out. By way of illustration, he considers the case of 'the stoppage of a firm which induces unemployment that in turn causes the failure of a grocer whose customer the unemployed workmen were'. He then adds that 'this grocer's market is not completely annihilated, however, and if he disappears there will be some space for other grocers to expand into.' (1939/I: 153).

Therefore, once depression has run its course, the system settles in a new neighbourhood of equilibrium, i.e. the third stage, namely recovery, sets in. At this point, a new innovation is likely to occur since the conditions for its emergence - both the stability and the reliability of the system of economic values - have been restored.

This simplified account is potentially complicated by differences in the 
magnitude of innovations as well as by the interference of external factors, such as, for instance, the intervention of the Central Bank. Under certain conditions, the economy may overshoot in the process of downward readjustment and, thus, remain in recession for longer than would otherwise have been the case.

However, for Schumpeter recession is of a transitory nature: Once bankruptcies have ceased, a phase of recovery is inevitable. These 'pathological' features of the cycle, as Schumpeter labels them, constitute the secondary waves of the business cycle, that occur in addition to the primary process and result from the diverse reactions to this process, such as speculation or self-reinforcing errors of expectation:

The cyclical clusters of errors, excesses of optimism and pessimism and the like are (...) not necessarily inherent in the primary process -which process would produce ups and downs and, be it particularly remembered, also losses without any error-although they can be adequately motivated by it. But now they acquire additional importance. Part of the phenomena of the secondary wave consists, in part, of nothing else.

(1939/I: 146)

However, even though these secondary waves may gather momentum and may, consequently, appear to be essential features of the cycle, they are merely 
effects derived from the working of the primary wave, itself a direct result of innovation. In Schumpeter's words:

The phenomena of this secondary wave may be and generally are quantitatively more important than those of the primary wave. Covering as they do a much wider surface, they are also much easier to observe; in fact they are what strikes the eye first, while it may be difficult, especially if the innovations are individually small, to find the torch responsible for the conflagration.

\section{Conclusion}

We began by highlighting the original features of Schumpeter's theory of business cycles arguing, in particular, that, in contrast to the majority of existing theories of growth and cycles, Schumpeter's approach provides a tentative answer to the question of how to integrate innovation with the study of business cycles.

We then proceeded to a discussion of Schumpeter's conception of the difference between dynamic and static analysis by way of examining his treatment of conventional growth factors, and saving in particular. Obviously, 
Schumpeter's approach to the analysis of business cycle is far from conventional.

The main reason, however, is that his conception of dynamics is directly linked to his view that innovations are at the core of the movements of a capitalist economy. It is only by taking account of this, that we can understand why Schumpeter concentrated on innovation and abstracted from all other growth factors whose effects, he maintained, cannot generate recurrent business cycles.

Finally, we discussed the mechanisms underlying the business cycle in Schumpeter's theory. This re-examination left several question unanswered. In particular, the relative neglect of significant aspects of the diffusion of innovation highlighted in this chapter constitutes a major shortcoming of Schumpeter's approach. What seems to be the case is that Schumpeter asserts rather than explains the cumulative nature of innovation. More generally, Schumpeter fails to describe the succession of events; he does not provide a detailed analysis of the mechanisms that link the scarcity of entrepreneurial abilities to the 'swarm-like' appearance of imitators and to the diffusion of innovations, at any given point in time. As Kuznets has emphasized, one is permitted to wonder why, given the existence of an infinite supply of possible innovations (including inventions and other combinations), an entrepreneurial genius should systematically manage to postpone the appearance of the next 
pioneer on the scene until a particular innovation has been imitated and diffused to such an extent that the disturbances of the equilibrium position should stop even this genius in his own pace. ${ }^{15}$.

Nevertheless, with Witt it should be stressed that this flaw in Schumpeter's theory later proved to be the vantage point for modern adaptations of his theory of innovation. ${ }^{16}$ From this point of view, Schumpeter's desire to see others verify and criticize his ideas in the light of further evidence has been fulfilled. Today, there is indeed a vast literature on industrial innovation and $R \& D$, even though its relation to Schumpeter's work is often regrettably tenuous.

15 See S. Kuznets 1940: 262.

16 See U. Witt 1995: 85. 


\section{Bibliography}

Aftalion A. (1913), Les crises périodiques de surproduction, Paris: M. Rivière et $C^{\text {ie }}$.

Aghion, P. and Howitt, P. (1998), Endogenous Growth Theory, Cambridge (Mass): MIT Press.

Arena, R. and Festré, A.(1996) 'Banks, credit and the financial system in Schumpeter: an interpretation’ in L. Moss (ed.), Joseph Schumpeter, Historian of economics, London:Routledge.

Date, K. (1961) 'The Relation of Cycles and Trends in Schumpeter's Model', Waseda Economic Papers 5: 22-34. Reprinted in J. Cunningham Wood (ed.), J.A. Schumpeter:Critical Assessments, vol.II (pp. 349-359), London: Routledge, 1991.

Elliot, J. E. (1985) ‘Schumpeter’s Theory of Economic Development and Social Change : Exposition and Assessment', International Journal of Social Economics 12: 6-33. Reprinted J. Cunningham Wood (ed.), J. A. Schumpeter:Critical Assessments, vol.IV (pp. 324-357), London: Routledge, 1991. 
Freeman, C. (1993) 'Schumpeter’s Business Cycles Revisited’ in U. Witt (ed.), Evolutionary Economics (pp. 17-38), Aldershot: Edward Elgar.

Hansen, A.H. (1951) 'Schumpeter’s Contribution to Business Cycle Theory’, Review of Economic Statistics 33: 129-132. Reprinted in J. Cunningham Wood (ed.), J. A. Schumpeter: Critical Assessments, vol.I (pp. 208-213), London: Routledge, 1991.

Kuznets, S. (1940) ‘Schumpeter’s Business Cycles’, American Economic Review 30(2): 257-271.

Madaràsz, A. (1991) 'Schumpeter’s Theory of Economic Development'. Reprinted in J.Cunningham Wood (ed.), J. A. Schumpeter: Critical Assessments, vol.III (pp. 218-240), London: Routledge, 1991.

Perroux, F. (1965), La pensée économique de Joseph Schumpeter, Geneva: Editions Droz.

Samuelson, P. A. (1943), 'Dynamics, statics, and the stationary state', Review of Economic Statistics 25: 58-68. 
Schumpeter, J. A. (1908), Das Wesen und der Hauptinhalt der Theorischen Nationalokonomie, Leipzig: Duncker und Humblot.

---- (1917) 'Das Sozial Produkt und die Rechenpfennige : Glossen und Beitrage zur Geldtheorie von Heute’, Archiv für Sozialwissenschaft 44: 627-715.

Translated from German by A. W. Marget, 'Money and the Social Product', International Economic Papers 6, 1956.

---- (1934) The Theory of Economic Development, Cambridge (Mass): Harvard University Press.

---- (1936), ‘Review of Keynes’ General Theory of Employment, Interest and Money’, Journal of the American Statistical Association, pp. 791-795.

---- (1939) Business Cycles, McGraw-Hill Book Company, 2 volumes.

---- (1952) Ten Great Economists. From Marx to Keynes, London: Allen \& Unwin.

---- (1954) History of Economic Analysis, London: Allen and Unwin.

Staley C. E. (1986), ‘Schumpeter’s Business Cycles’, New York Economic 
Review XVI: 300-313.

Witt, U. (1995), 'Schumpeter vs. Hayek: two approaches to evolutionary economics’ in G.Meijer (ed.), New Perspectives on Austrian Economics (pp. 81-101), London: Routledge.

Wolfson, R. J. (1958), 'The Economic Dynamics of Joseph Schumpeter', Economic Development and Cultural Change, 7: 31-54. Reprinted in J. Cunningham Wood (ed.), J. A. Schumpeter: Critical Assessments, vol.II (pp. 191-215), London: Routledge, 1991. 